Nota

\title{
Micropropagação de violeta africana ${ }^{(1)}$
}

\author{
GIULIO CESARE STANCATO(2), FERNANDA CRISTINA SIMÕES NÉRI(2) \\ e ARMANDO REIS TAVARES ${ }^{(3)}$
}

\begin{abstract}
RESUMO
Na micropropagação são empregados meios nutritivos que fornecem ao propágulo as substâncias essenciais para o crescimento. Entre os componentes dos meios nutritivos está o grupo de fitorreguladores. Na micropropagação da violeta africana (Saintpaulia ionantha Wendl.) foi constatado que existe uma gama de protocolos já dsenvolvidos, no que diz respeito ao uso de fitorreguladores. O objetivo deste trabalho foi de estabelecer qual o protocolo que mais plântulas produzem bem como o maior acúmulo de matéria seca , a partir de explantes de folha, até a fase de aclimatização das plântulas. Os meios se diferenciaram pela fonte e concentração de citocinina e auxina, ou seja: meio A: cinetina $\left(0,2 \mathrm{mg} . \mathrm{L}^{-1}\right)$ e ácido naftaleno-acético $\left(0,2 \mathrm{mg} \cdot \mathrm{L}^{-1}\right)$; meio B: -benzilaminipurina $\left(0,5 \mathrm{mg} \cdot \mathrm{L}^{-1}\right)$ e ácido naftaleno-acético (0,1 mg.L-1 $)$; meio C: sem fitorreguladores; D: 6-benzilaminopurina $\left(0,5 \mathrm{mg} . \mathrm{L}^{-1}\right)$; meio E: 6-benzilaminopurina (0,05 mg. $\left.\mathrm{L}^{-1}\right)$ e ácido naftaleno-acético $\left(0,1 \mathrm{mg} . \mathrm{L}^{-1}\right)$; meio $\mathbf{F}$ : 6- benzilaminopurina $\left(0,08 \mathrm{mg} . \mathrm{L}^{-1}\right)$ e ácido indol-acético $\left(2,0 \mathrm{mg} . \mathrm{L}^{-1}\right)$. Em decorrência, tendo em vista as variáveis estudadas, o experimento constou de onze tratamentos com diferentes concentrações e fontes de fitorreguladores para as três etapas. Nas primeira etapa (estabelecimento), visando à indução das brotações, é necessário incluir fitorreguladores no meio de cultura (auxina e citocinina), sendo que o meio nutritivo A se mostrou mais eficiente que os demais. Para a segunda etapa (multiplicação), os explantes do meio nutritivo que continha cinetina e ácido naftaleno-acético (primeira fase) e que foram transferidos para o meio $\mathrm{D}$, foram os que mostraram desenvolvimento uniforme das brotações e produziram o maior número de brotações viáveis por explante. Para a terceira etapa (enraizamento), as brotações vindas dos meios $\mathrm{B}>\mathrm{E}$ e que foram enraizadas no meio $\mathrm{F}$, apresentaram as maiores taxas de incremento de matéria seca na parte aérea e nas raízes, sendo o meio mais indicado para a micropropagação da violeta africana.
\end{abstract}

Palavras-chave: auxina, citocinina, Saintpaulia ionantha

\section{ABSTRACT \\ African violet micropropagation}

Nutritive media in micropropagation are sources of essential compounds for the propagules growth. Among the nutritive media components is the group of plant growth regulators. For micropropagation of the African violet (Saintpaulia ionantha Wendl.) there are many well developed protocols. This work was carried out to compare some auxin:cytokinin ratios for African violet micropropagation and to indicate the better ratio for size and weight of plantlets from leaves explants towards the seedlings acclimatization phase. The sis media studied differ from each other by the source and the concentration of auxins and cytokinins, as follows: A, kinetin $\left(0.2 \mathrm{mg} . \mathrm{L}^{-1}\right)$ and naphthaleneacetic acid $\left(0.2 \mathrm{mg} . \mathrm{L}^{-1}\right) ; \mathbf{B}, 6$-benzyladenine $\left(0.5 \mathrm{mg} . \mathrm{L}^{-1}\right)$ and naphthaleneacetic acid $\left(0.1 \mathrm{mg} . \mathrm{L}^{-1}\right)$; $\mathbf{C}$, without plant regulators; D, 6-benzyladenine (0.5 mg. $\left.\mathrm{L}^{-1}\right)$; E, 6-benzyladenine $\left(0.05 \mathrm{mg} . \mathrm{L}^{-1}\right)$ and naphthaleneacetic acid $\left(0.1 \mathrm{mg} . \mathrm{L}^{-1}\right)$; F , 6-benzyladenine $(0.08$ $\left.\mathrm{mg} . \mathrm{L}^{-1}\right)$; indoleacetic acid $\left(2.0 \mathrm{mg} . \mathrm{L}^{-1}\right)$. Eleven treatments were tested, consisting of different sources and concentrations of the plant growth regulators for the three phases. During the first phase (establishment), the inclusion of plant growth regulators (auxin and cytokinin) was necessary in order to induce the shoot formation. Differences between sources and concentrations of the plant growth regulators were observed and the medium with kinetin $\left(0.2 \mathrm{mg} . \mathrm{L}^{-1}\right)$ and naphthaleeneacetic acid $\left(0.2 \mathrm{mg} . \mathrm{L}^{-1}\right)$ was more efficient than the others. At the second phase (multiplication), plants removed from the medium with kinetin and naphthaleneacetic acid of the first phase and transferred to a medium with 6-benzyladenine $(0.5 \mathrm{mg} . \mathrm{L}-1)$ showed uniform development and produced the highest number of viable shoots by explants. At the third phase (rooting), the shoot from the media $\mathbf{B}, \mathbf{E}$ and $\mathbf{F}$, showed the higher root and shoot dry matter increasing.

Keywords: auxin, cytokinin, Saintpaulia ionantha

(1) Recebido para publicação em 19/03/2008 e aprovado em 11/03/2010

(2) Centro de Horticultura, Instituto Agronômico (IAC), Caixa Postal 28, CEP 130102-902, Campinas, SP. E-mail: stancato@iac.sp.gov.br

${ }^{(3)}$ Instituto de Botânica (IBt)

Abreviaturas: AIA (ácido indol-acético); ANA (ácido naftaleno-acético); 6-BA (benzilaminopurina); KIN (cinetina) 


\section{INTRODUÇÃO}

A micropropagação de plantas é considerada uma das áreas de maior êxito da biotecnologia, tendo conquistado uma posição de destaque na obtenção de plântulas, no melhoramento genético, no intercâmbio, conservação e manejo de germoplasma. E em outras aplicações, contribuindo para a produção de plantas com excelente estado fitossanitário (GIACOMETTI, 1990). De acordo com MURASHIGE (1974), a obtenção de plântulas através dos métodos de micropropagação é alcançada mediante o desenvolvimento de uma seqüência de três etapas: a) seleção do tipo de explante, desinfestação e cultura em meio nutritivo sob condições assépticas; b) multiplicação dos propágulos através de sucessivas sub-culturas; c) transferência das partes aéreas produzidas para um meio de enraizamento e o subseqüente transplantio das plântulas para vaso ou solo.

$\mathrm{Na}$ micropropagação são empregados meios nutritivos que fornecem ao propágulo as substâncias essências do crescimento. Entre os componentes dos meios nutritivos está o grupo dos fitorreguladores. De acordo com RAVEN, EVERT e EICHHORN (2001) são substâncias sintéticas que quando aplicadas às plantas induzem o aparecimento de efeitos semelhantes aos produzidos pelos hormônios vegetais naturais. Entre os grupos mais empregados na micropropagação está o grupo das auxinas que promovem o crescimento por um efeito no alongamento celular, principalmente quando aplicadas a segmentos de plantas dos quais foi eliminada a fonte endógena de auxina (RAVEN, EVERT e EICHHORN, 2001). Desse grupo de reguladores de crescimento os mais conhecidos são: 2,4-D (ácido 2,4-diclorofenoxiacético), ANA (ácido naftalenoacético) e AIB (ácido indol-butírico). As citocininas são substâncias derivadas da adenina e promovem a divisão celular, em geral, por uma interação com as auxinas (RAVEN, EVERT e EICHHORN, 2001). Entre as citocininas sintéticas mais usadas estão a KIN (cinetina) e 6-BA (6-benzilaminopurina); entre as naturais estão a 2ip (2-isopenteniladenina) e zeatina (ZEA), [n 6 -(4-hidroxi-3-metilbut-2enil) aminopurina].

Na micropropagação da violeta africana, que é considerada uma das mais populares plantas ornamentais, existindo no mercado mundial mais de cinqüenta cultivares, foi constatado que existe uma gama de protocolos já desenvolvidos (START e CUMMING, 1976; COOKE, 1977; BILKEY et al., 1978; SMITH e NORRIS, 1983; LERCARI et al., 1986; ALTAFINI e GALLO, 1998; MOGES et al., 2003; RAZDAN, 2003; MOGES et al. 2004; SENEVIRATNE e WIJESUNDARA, 2004) e que a quantidade de plântulas obtidas e o tempo gasto durante o processo, quando da aplicação deste ou daquele protocolo, têm apresentado diferenças significativas e está diretamente relacionado com a fonte e dosagem dos fitorreguladores empregados. Assim sendo, fica claro que a escolha do protocolo e dos fitorreguladores envolvidos, pode acelerar ou retardar o processo de obtenção de plântulas de violeta africana in vitro, bem como viabilizar o seu emprego comercial.

Tendo em vista os fatos expostos, o objetivo deste trabalho foi comparar algumas relações auxinas:citocininas utilizadas para a micropropagação da violeta africana, a partir de explantes de folha, até a fase de aclimatização das plantas e indicar qual relação é mais produtiva em termos de número de plântulas obtidas assim como o acúmulo de matéria seca acumulada

\section{MATERIAL E MÉTODOS}

Este trabalho foi desenvolvido com Saintpaulia ionantha Wendl. (Gesneriaceae), cultivar Nicole. A obtenção de plântulas se deu através do emprego da técnica de micropropagação, a partir da indução de gemas adventícias, pela organogênese direta. Para a obtenção de plântulas enraizadas, o sistema de micropropagação foi executado a partir da seqüência normal de três etapas, ou seja, o estabelecimento, a multiplicação e o enraizamento, respectivamente. $\mathrm{O}$ meio de cultura básico utilizado foi o de MURASHIGE e SKOOG (1962), sendo acrescentado pantotenato de cálcio $\left(1,0 \mathrm{mg} . \mathrm{L}^{-1}\right)$ sacarose $\left(20,0\right.$ g. $\left.\mathrm{L}^{-1}\right)$, agar $\left(6,0\right.$ g. $\left.\mathrm{L}^{-1}\right)$ e pH 5,8 antes da esterilização em autoclave.

Os meios se diferenciaram pela fonte e concentração de auxina e citocinina, ou seja: meio A: cinetina $(0,2$ $\left.\mathrm{mg} . \mathrm{L}^{-1}\right)$ e ácido naftaleno-acético $\left(0,2 \mathrm{mg} . \mathrm{L}^{-1}\right)$; meio B: 6benzilaminopurina $\left(0,5 \mathrm{mg} . \mathrm{L}^{-1}\right)$; meio $\mathbf{C}$ : sem fitorreguladores; meio D: 6-benzilaminopurina; meio $\mathbf{E}$ : 6-benzilaminopurina $\left(0,05 \mathrm{mg} \cdot \mathrm{L}^{-1}\right)$ e ácido naftaleno-acético $\left(0,1 \mathrm{mg} \cdot \mathrm{L}^{-1}\right)$; meio F: 6-benzilaminopurina $\left(0,08 \mathrm{mg} \cdot \mathrm{L}^{-1}\right)$ e ácido indol-acético $\left(2,0 \mathrm{mg} \cdot \mathrm{L}^{-1}\right)$. Tendo em vista as variáveis estudadas, o experimento foi composto por onze tratamentos com diferentes concentrações de fitorreguladores, para as três etapas, conforme apresentado na tabela 1.

A partir de plantas matrizes previamente selecionadas, foram utilizados seguimentos foliares próximos às nervuras de folhas adultas completamente expandidas. As folhas coletadas foram mantidas em água destilada e Tween 20 a $0,01 \%$, sob agitação por uma hora. Em câmara asséptica, foram imersas em etanol $70 \%$ por dez segundos; em seguida foi realizada a desinfestação em solução de hipoclorito de sódio $30 \%$, por quinze minutos. Após a desinfestação seguiram-se lavagens com água destilada, deionizada e esterilizada repetidas vezes. $\mathrm{O}$ isolamento dos explantes foi realizado em câmara de fluxo laminar, sob condições assépticas, desprezando-se as bordas sendo que um terço dos explantes foi introduzido no meio de cultura.

Três explantes foram incubados em frascos de vidro com tampa plástica, contendo aproximadamente $50 \mathrm{~mL}$ do meio nutritivo. Inicialmente, os frascos foram mantidos em sala de incubação, durante uma semana, no escuro. Em seguida, foram transferidos para a luz, sendo mantidos em prateleiras de aço iluminadas com lâmpadas fluorescentes (40-50 $\mu \mathrm{E} . \mathrm{cm}$ $\left.{ }^{-2} \cdot \mathrm{s}^{-1}\right)$, permanecendo por quatro semanas, sob fotoperíodo de dezesseis horas. A temperatura foi mantida na faixa de $22-25^{\circ} \mathrm{C}$. O experimento teve duração de treze semanas sendo quatro semanas para a etapa de estabelecimento, cinco semanas para a etapa de multiplicação e quatro semanas para a etapa do enraizamento, para o qual foram utilizadas as maiores 
Tabela 1. Tratamentos empregados no experimento para obtenção de plântulas de Saintpaulia ionantha Wendl., no que diz respeito à aplicação de fitorreguladores.

Table 1. Treatments utilized in the experiment for obtaining plantlets of Saintpaulia ionantha Wendl., cv. Nicole, concerning to application of plant growth regulators.

\begin{tabular}{ccc}
\hline ESTABELECIMENTO & MULTIPLICAÇÃO & ENRAIZAMENTO \\
\hline INOCULATION & MULTIPLICATION & ROOTING \\
\hline A (KIN 0,2 X ANA 0,2) & D (6-BA 0,5) & F-BA 0,08 x AIA 2,0) \\
A (KIN 0,2 X ANA 0,2) & C (sem fitohormonio) $)^{*}, 08$ X AIA 2,0) \\
A (KIN 0,2 X ANA 0,2) & C (sem fitohormonio) & C (sem fitohormonio) \\
B (6-BA 0,5 X ANA 0,1) & E (6-BA 0,05 X ANA 0,1) & F (6-BA 0,08 X AIA 2,0) \\
B (6-BA 0,5 X ANA 0,1) & C (sem fitohormonio) & F (6-BA 0,08 X AIA 2,0) \\
B (6-BA 0,5 X ANA 0,1) & C (sem fitohormonio) fitohormonio) \\
C (sem fitohormonio) & D (6-BA 0,5) & F (6-BA 0,08 X AIA 2,0) \\
C (sem fitohormonio) & D (6-BA 0,5) & C (sem fitohormonio) \\
C (sem fitohormonio) & E (6-BA 0,05 X ANA 0,1) & F (6-BA 0,08 X AIA 2,0) \\
C (sem fitohormonio) & E (6-BA 0,05 X ANA 0,1) & C (sem fitohormonio) \\
C (sem fitohormonio) & C (sem fitohormonio) & C (sem fitohormonio)
\end{tabular}

* English $=$ without phytohormone

brotações provenientes da etapa anterior, sem a necessidade de estabelecimento de sub-culturas.

\section{RESULTADOS E DISCUSSÃO}

Os resultados mostrados na tabela 2 indicam que é necessária a presença de fitorreguladores na fase de estabelecimento, durante a micropropagação de violeta africana, uma vez que a quantidade de matéria seca acumulada nos explantes nos meios que continham auxina e citocinina foi bem maior. Esta etapa é importante, pois ocorreu o desenvolvimento de gemas adventícias, a partir de tecidos meristemáticos presentes no explante da folha, os quais originaram as brotações e os primórdios foliares. De acordo com GRATTAPAGLIA e MACHADO (1998), a presença de fitorreguladores exógenos induziu o início do processo de organogênese direta, ou seja, o surgimento direto de gemas a partir de tecidos que apresentam potencial morfogenético na planta in vivo, mas que, em geral, não se expressa. A não passagem pelo estádio de calo é muito importante já que a fidelidade genética neste caso é geralmente bastante alta, provavelmente devido ao fato que as gemas adventícias surgem a partir de uma ou duas camadas de células. Os balanços KIN X ANA e 6-BA $\mathrm{X}$ ANA promoveram os maiores acúmulos de matéria seca nos explantes, o que pode ser traduzido como uma maior competência na promoção dos processos morfogenéticos. Os dados obtidos experimentalmente estão de acordo com a literatura (GRATTAPAGLIA e MACHADO, 1998), pois o que se busca nesta fase é o estabelecimento da cultura in vitro, uma vez que os explantes, sob ação dos fitorreguladores, sofrem mudanças na sua constituição.

Para a segunda etapa, ou seja, a etapa de multiplicação, os dados mostrados na tabela 3 revelam que esta etapa foi a mais longa e que a presença de fitorreguladores exógenos foi importante para induzir a formação de brotações. Embora o principal objetivo desta etapa é o de produzir o maior número possível de plântulas, no menor espaço de tempo, alguns aspectos qualitativos foram igualmente importantes e devem ser considerados. Nos tratamentos A $>$ D e B $>$ E, considerando as etapas de estabelecimento e multiplicação simultaneamente, ocorreu maior número de brotações formadas, porém, o importante foi a reprodutibilidade do sistema, ou seja, foi conseguida uma taxa média satisfatória com o mínimo de variação de explante para explante, havendo pouca variação das partes aéreas obtidas. Com exceção dos tratamentos $\mathrm{A}>\mathrm{D}$ e $\mathrm{B}>\mathrm{E}$, a maior quantidade de matéria seca acumulada por brotação se deu no tratamento sem a presença de fitorreguladores, no entanto o número de brotações e a quantidade de matéria seca acumulada por brotação foram grandezas inversamente proporcionais.

Quando o objetivo é a maior produção de plântulas in vitro, os tratamentos $\mathrm{A}>\mathrm{D}$ e $\mathrm{B}>\mathrm{E}$ mostraram-se os mais indicados, principalmente o tratamento $\mathrm{A}>\mathrm{D}$, em relação ao elevado número de brotações produzidas (tabela 3 ). Os resultados obtidos neste trabalho estão em acordo com os números de brotações obtidas por outros autores (START e CUMMING, 1976; COOKE,1977; BILKEY et al. 1978 e LERCARI et al, 1986) porém, o tratamento $\mathrm{A}>\mathrm{D}$ indica que a relação de 1:1 auxina:citocinina, na fase de estabelecimento, e de 0: 1 na fase de multiplicação, produziram a maior quantidade de brotação, quando comparada aos demais balanços hormonais testados. De acordo com GRATTAPAGLIA e MACHADO (1998), as citocininas constituem um grupo de fitorreguladores indispensável para a indução e proliferação de gemas adventícias, sendo a 6-BA muito eficaz para promover multiplicação em diversas espécies vegetais. De 
acordo com GRATTAPAGLIA e MACHADO (1998), a 6BA é a citocinina mais eficaz para promover a proliferação de partes aéreas e economicamente mais viável devido ao seu menor custo. Por outro lado, as concentrações de auxina são frequentemente baixas se comparadas às das citocininas para manter um balanço auxina:citocinina igual ou menor que um. Concentrações excessivas de auxina podem inibir a proliferação de brotos ou favorecer demasiadamente o enraizamento ou a formação de calo, sendo o ANA a auxina mais utilizada em meios de multiplicação (GRATTAPAGLIA e MACHADO, 1998).

Os tratamentos que não continham fitorreguladores na fase de multiplicação, ou seja, A > C e B > C, com exceção do tratamento $\mathrm{C}>\mathrm{C}$, apresentaram valores intermediários de acúmulo de matéria seca por brotação (tabela 3), porém, o número de brotações foi menor, quando comparado aos tratamentos com fitorreguladores. Estes dados reforçam o pressuposto de que a presença de fitorreguladores no meio de cultura pode induzir um maior número de brotações, mostrando sua necessidade na produção comercial de plântulas de violeta africana in vitro. $\mathrm{O}$ tratamento $\mathrm{C}>\mathrm{C}$ apresentou o maior acúmulo de matéria seca por brotação, porém, o número de brotações foi o menor obtido, sendo que aproximadamente uma brotação por explante, que é considerado muito baixo para os padrões comerciais (COOKE, 1977 e BILKEY et al., 1978).

Os dados apresentados na tabela 4, que incluem a etapa de enraizamento, indicam que as plântulas obtidas no tratamento $\mathrm{B}>\mathrm{E}>\mathrm{F}$ apresentaram os maiores acúmulos de matéria seca na parte aérea e nas raízes e, consequentemente, o maior acúmulo de matéria seca total. Plântulas obtidas no tratamento A > D $>\mathrm{F}$ mostraram o segundo maior acúmulo. Estes resultados comprovam a necessidade do uso de fitorreguladores na micropropagação de violeta africana, durante a fase de enraizamento, sendo, neste trabalho, empregado um balanço auxina:citocinina da ordem de 25:1. Os demais tratamentos mostraram valores inferiores, principalmente considerando o número de brotações por explante (tabela 3 ). O processo de micropropagação por si só pode estimular um rejuvenescimento da cultura que se manifesta na forma de um incremento na taxa de enraizamento, sendo que o tamanho das brotações formadas durante a fase de multiplicação determina, em grande parte, o sucesso do enraizamento. De acordo com GRATTAPAGLIA e MACHADO (1998), partes aéreas pequenas, em geral, não enraízam bem, o que foi verificado neste trabalho nos tratamentos sem fitorreguladores em pelo menos uma das fases da micropropagação.

A rizogênese pode ser dividida em indução, iniciação e alongamento, sendo que as duas primeiras fases respondem ou dependem da presença de auxina. Neste trabalho, os maiores acúmulos de matéria seca de raízes ocorreram em plântulas cultivadas em meio na presença de auxina (tabela 4), sendo difícil determinar uma condição in vitro na qual todas as fases do enraizamento possam ocorrer normalmente e de preferência sem demandar manipulação adicional de uma fase para outra.

Em comparação com outros trabalhos (START e CUMMING, 1976; COOKE, 1977; BILKEY et al., 1978 e MOGES, 2003), as quantidades de matéria seca acumulada nas raízes, neste trabalho, estiveram aquém do obtido por esses autores. É possível que outros fatores tenham contribuído para um enraizamento menor. Trabalhos como os de LANE (1979), HASEGAWA (1980), VALLES e BOXUS (1987) citados por GRATTAPAGLIA e MACHADO (1998), entre outros, obtiveram boas taxas de enraizamento diluindo a concentração salina do meio de cultura, principalmente de macronutrientes. Porém, diferentes tipos e concentrações de auxina são as variáveis que, em geral, mais influenciam o enraizamento. A adição de outros fitorreguladores é considerada desnecessária ou prejudicial. Porém, este fato não foi observado no presente trabalho, já que o meio de cultura empregado continha 6-BA, uma citocinina.

A partir dos resultados obtidos ficou claro que existem diferenças significativas entre os diversos protocolos para a micropropagação da violeta africana, principalmente no que diz respeito ao número e tamanho dos explantes, bem como em relação ao tempo necessário para a obtenção de plântulas.

\section{CONCLUSÕES}

A seqüência de meios $\mathrm{B}>\mathrm{E}>\mathrm{F}$ apresentou a maior quantidade de plântulas e as maiores taxas de incremento de matéria seca na parte aérea e nas raízes

É necessário o emprego de fitorreguladores na micropagação da violeta africana, principalmente nas fases de estabelecimento e multiplicação

A quantidade de explantes produzidos justifica o emprego da micropropagação in vitro.

\section{REFERÊNCIAS}

ALTAFINI, V.L.; GALLO, L.A. Efeito do BAP e da concentração de nutrientes do meio de cultura no desenvolvimento de explantes foliares de violeta africana (Saintpaulia ionantha H. Wendl.) in vitro. Ecossistema, v. 23, p. 39-42, 1998.

BILKEY, P.C.; MCCOWN, B.H.; HILDEBRANDT,A.C. Micropropagation of African violets from petiole cross-sections. HortScience, v. 13, n.1, p. 37-38, 1978.

COOKE, R.C. Tissue culture propagation of African violets. HortScience, v.12, n.1, p. 549, 1977.

GIACOMETTI, D.C. Impacto atual da cultura de tecidos de plantas. In: Técnicas e aplicações da cultura de tecidos de plantas. TORRES, A.C. e CALDAS, L.S. (ed.), ABCTP/ EMBRAPA-CNPH. p.19-25, 1990.

GRATTAPAGLIA, D; MACHADO,M.A. Micropropagação. In: Cultura de tecidos e transformação genética de plantas. TORRES, A.C.; CALDAS, L.S.; BUSO, J.A. (ed.), Volume 1. ABCTP/EMBRAPA-CNPH. p. 183-260, 1998.

LERCARI, B.; TOGNONI, F.; ALSELMO, C.; CHAPEL, D. 
Photocontrol of in vitro differentiation in Saintpaulia ionantha leaves and Lycopersicon esculentum cotyledons. Physiologia Plantarum, v. 67, p. 340-344, 1986.

MOGES, A.D.; SHIBLI, R.A.; KARAM, N.S. Slow growth in vitro preservation of African violet (Saintpaulia ionantha Wendl.). Advance Horticultural Science, v. 17, n. 4, p. 223 230, 2003.

MOGES, A.D.; SHIBLI, R.A.; KARAM, N.S. Cryopreservation of African violet (Saintpaulia ionantha Wendl.) shoot tips. In vitro Cellular Development, v. 40, n. 4, p. 389-395, 2004

MURASHIGE, T. Plant propagation through tissue culture. Annual Review of Plant Physiology, v. 25, p. 135-166, 1974.

MURASHIGE, T.; SKOOG, F. A revised medium for rapid growth and bioassays with tobacco tissue cultures. Physiolo- gia Plantarum, v. 15, p. 473-497, 1962.

RAZDAN, M.K. Introduction to plant tissue culture. Science Publishers (ed.). p. 458, 2003.

RAVEN, P.H.; EVERT, R.F.; EICHHORN, S.E. Biologia Vegetal. Guanabara Koogan S.A. (ed). p. 906, 2001.

SENEVIRATNE, K.A.C.N.; WIJESUNDARA, D.S.A. News African violets (Saintpaulia ionantha Wendl.) induced by colchicines. Current Science India, v. 87, n. 2, p. 138-140, 2004.

SMITH, R.H.; NORRIS, R.E. In vitro propagation of African violets chimeras. HortScience, v. 18, n. 4, p. 436-437, 1983.

START, N.D.; CUMMING, B.G. In vitro propagation of Saintpaulia ionantha Wendl. HortScience, v.11, n. 3, p. 204-206, 1976.

Tabela 2. Quantidade de material seca acumulada (mg) em explantes foliares, no ensaio que avaliou diferentes fontes e dosagens de fitorreguladores vegetais, durante a etapa de estabelecimento, na micropropagação de Saintpaulia ionantha Wendl. cv. Nicole, após quatro semanas de incubação. $(\mathrm{n}=10)$

Table 2. Amount of dry material accumulated $(\mathrm{mg})$ in foliar explants, in the experiment that evaluated the source and quantity of plant growth regulators, during the establishment phase, in the micropropagation of Saintpaulia ionantha Wendl. cv. Nicole, after four weeks of incubation. $(n=10)$

\begin{tabular}{ccc}
\hline MEIO DE CULTURA & MÉDIA & DESVIO PADRÃO \\
\hline CULTURE MEDIUM & AVERAGE & STANDARD DEVIATION \\
\hline A ( KIN 0,2 X ANA 0,2) & $8,23 \mathrm{a}^{1,2}$ & 0,36 \\
B ( 6-BA 0,5 X ANA 0,1) & $7,06 \mathrm{~b}$ & 0,39 \\
C (sem fitorreguladores) & $5,34 \mathrm{c}$ & 0,24 \\
\hline
\end{tabular}

${ }^{1}$ teste $\mathrm{F}=185,95$

${ }^{2}$ letras iguais na coluna não diferem estatisticamente entre si pelo teste de Tukey a 5\%

${ }^{2}$ values followed by different letters are statistically different $(P<0.05)$ 
Tabela 3. Quantidade de matéria seca (mg) acumulada por brotação e número de brotações, no ensaio que avaliou o efeito de fitorreguladores na micropropagação de Saintpaulia ionantha Wendl. cv. Nicole, a partir de explantes foliares, durante a etapa de multiplicação, após cinco semanas de incubação. $(\mathrm{n}=10)$

Table 3. Amount of dry matter accumulated ( $\mathrm{mg}$ ) in buds and number of buds in the experiment that evaluated the effect of application of plant growth regulators in the micropropagation of Saintpaulia ionantha Wendl. cv. Nicole, from foliar explants, during the multiplication phase, after five weeks of incubation. $(n=10)$

\begin{tabular}{|c|c|c|}
\hline TRATAMENTO & MATÉRIA SECA & $\mathrm{N}^{\circ}$ DE BROTAÇÕES \\
\hline TREATMENT & DRIED MATTER & NR. SPROUTS \\
\hline $\mathrm{A}>\mathrm{D}$ & $8,25 \mathrm{c}\left(0,35^{1,2}\right)$ & $15,5 \mathrm{a}\left(0,71^{3}\right)$ \\
\hline $\mathrm{A}>\mathrm{C}$ & $5,87 \mathrm{e}(0,32)$ & $5,8 \mathrm{c}(0,79)$ \\
\hline $\mathrm{A}>\mathrm{C}$ & $5,75 \mathrm{e}(0,41)$ & $5,6 \mathrm{~cd}(0,70)$ \\
\hline $\mathrm{B}>\mathrm{E}$ & $10,11 b(0,39)$ & $8,5 \mathrm{~b}(1,08)$ \\
\hline $\mathrm{B}>\mathrm{C}$ & $6,96 \mathrm{~d}(0,21)$ & $4,7 \mathrm{~d}(0,67)$ \\
\hline $\mathrm{B}>\mathrm{C}$ & $6,92 \mathrm{~d}(0,23)$ & $5,0 \mathrm{~cd}(0,67)$ \\
\hline $\mathrm{C}>\mathrm{D}$ & $9,97 b(0,40)$ & $2,4 \mathrm{ef}(0,52)$ \\
\hline $\mathrm{C}>\mathrm{D}$ & $9,95 \mathrm{~b}(0,19)$ & $1,9 \mathrm{ef}(0,57)$ \\
\hline $\mathrm{C}>\mathrm{E}$ & $9,79 b(0,36)$ & $2,6 \mathrm{e}(0,52)$ \\
\hline $\mathrm{C}>\mathrm{E}$ & $9,89 \mathrm{~b}(0,21)$ & $2,5 \mathrm{e}(0,53)$ \\
\hline $\mathrm{C}>\mathrm{C}$ & $13,08 \mathrm{a}(1,06)$ & $1,4 \mathrm{f}(0,52)$ \\
\hline
\end{tabular}

${ }^{1}$ teste $\mathrm{F}$ (matéria seca brotações) $=256,55$; teste $\mathrm{F}$ (número de brotações) $=357,13 \quad{ }^{2}$ desvio padrão pelo teste de Tukey a 5\% $\quad{ }^{1}$ test $F$ (bud dry matter) $=256,55 ;$ F test $($ number of buds) $=357,13$ letters are statistically different $(P<0.05)$
${ }^{3}$ letras iguais na coluna não diferem estatisticamente ${ }^{2}$ standard deviation $\quad{ }^{3}$ values followed by different

Tabela 4. Quantidade de matéria seca (mg) acumulada em plântulas, no experimento que avaliou o efeito de fitorreguladores na micropropagação de Saintpaulia ionantha Wendl. cv. Nicole, a partir de explantes foliares, após quatro semanas de incubação, durante a etapa de enraizamento. $(\mathrm{n}=10)$

Table 4. Amount of dry matter accumulated ( $\mathrm{mg}$ ) in plantlets in the experiment that evaluated the effect of application of plant growth regulators in the micropropagation of Saintpaulia ionantha Wendl. cv. Nicole, from foliar explants, after four weeks of incubation. $(n=10)$

\begin{tabular}{|c|c|c|c|}
\hline TRATAMENTO & MATÉRIA SECA TOTAL & MATÉRIA SECA PARTE AÉREA & MATERIA SECA RAÍZES \\
\hline TREATMENT & TOTAL DRIED MATTER & LEAF DRIED MATTER & ROOT DRIED MATTER \\
\hline $\mathrm{A}>\mathrm{D}>\mathrm{F}$ & $18,37 \mathrm{~b}\left(0,63^{1}\right)$ & $14,2 \mathrm{~b}\left(0,59^{2}\right)$ & $4,17 \mathrm{~b}\left(0,21^{3}\right)$ \\
\hline $\mathrm{A}>\mathrm{C}>\mathrm{F}$ & $12,26 f(0,20)$ & $9,04 \mathrm{e}(0,15)$ & $3,22 \mathrm{de}(0,15)$ \\
\hline $\mathrm{A}>\mathrm{C}>\mathrm{C}$ & $11,62 f(0,54)$ & $8,95 \mathrm{e}(0,28)$ & $2,67 \mathrm{fg}(0,40)$ \\
\hline $\mathrm{B}>\mathrm{E}>\mathrm{F}$ & $22,2 \mathrm{a}(0,87)$ & $16,95 \mathrm{a}(0,88)$ & $5,25 \mathrm{a}(0,42)$ \\
\hline $\mathrm{B}>\mathrm{C}>\mathrm{F}$ & $11,47 f(0,74)$ & $8,46 \mathrm{e}(0,56)$ & $3,01 \mathrm{efg}(0,34)$ \\
\hline $\mathrm{B}>\mathrm{C}>\mathrm{C}$ & $11,71 \mathrm{f}(0,42)$ & $8,69 \mathrm{e}(0,49)$ & $3,03 \mathrm{ef}(0,24)$ \\
\hline $\mathrm{C}>\mathrm{D}>\mathrm{F}$ & $16,14 \mathrm{c}(0,51)$ & $12,58 \mathrm{c}(0,43)$ & $3,56 \mathrm{~cd}(0,33)$ \\
\hline $\mathrm{C}>\mathrm{D}>\mathrm{C}$ & $15,04 \mathrm{~d}(0.90)$ & $12,5 \mathrm{c}(0,58)$ & $2,55 \mathrm{fg}(0,39)$ \\
\hline $\mathrm{C}>\mathrm{E}>\mathrm{F}$ & $14,31 \mathrm{de}(0,40)$ & $11,0 \mathrm{~d}(0,15)$ & $3,31 \mathrm{de}(0,39)$ \\
\hline $\mathrm{C}>\mathrm{E}>\mathrm{C}$ & $13,83 \mathrm{e}(0,64)$ & $11,31 \mathrm{~d}(0,54)$ & $2,52 \mathrm{~g}(0,32)$ \\
\hline $\mathrm{C}>\mathrm{C}>\mathrm{C}$ & $11,68 f(0,39)$ & $14,83 b(0,43)$ & $3,86 \mathrm{bc}(0,36)$ \\
\hline
\end{tabular}

${ }^{1}$ teste $\mathrm{F}($ matéria seca total $)=319,02$; teste $\mathrm{F}$ (matéria seca da parte aérea) $=311,07$; teste $\mathrm{F}$ (matéria seca de raízes) $=59,16 \quad{ }^{2}$ desvio padrão $\quad{ }^{3}$ letras iguais na coluna não diferem estatisticamente pelo teste de Tukey a $5 \% \quad{ }^{I} F$ test (total dry matter) $=319,02 ;$ F test (shoot dry matter) $=311,07 ;$ F test (root dry matter) $=$ $59,16 \quad{ }^{2}$ standard deviation $\quad{ }^{3}$ Values followed by different letters are statistically different $(P<0.05)$ 